\title{
Triadic classifications and triangular thinking: their use in urban planning and urban design
}

\author{
Barry Goodchild* \\ Sheffield Hallam University
}

\begin{abstract}
The aim of this paper is to explore the relationship between discourse and reality in the definition of spaces and places and more generally in relation to the planning process. In doing this, the aim is to show the pervasiveness and usefulness of triadic or three-way classifications. This paper starts with a distinction between the real, the imaginary and the symbolic and with the chronic uncertainty and unpredictability that this triad implies for the planning process. It goes on to discuss concepts of space as comprising a mixture of the perceived, the conceived and the experienced. Finally, it looks at attempts to define places as the object of urban design and comprising a mixture of physical form, activities and conceptions.
\end{abstract}

Keywords: planning theory, spaces, places.

Discourse analysis has been a popular and highly influential means of analysing policies over the past decade. Many examples can be given of its use - for example in housing policy and housing studies (Goodchild and Cole, 2001: Hastings, 2000); urban and regional planning (Richardson and Jensen, 2003: Tett and Wolfe, 1991); and in environmental policy (Feindt and Oels, 2005: Hajer, 1995). These are all policy fields where technical and political considerations interact with one another in defining the problem and its solution. By virtue of its emphasis on difference - difference of interpretation and difference in relation to who is and who is not included - discourse analysis is, moreover, a key element for postmodern research methodologies. In postmodern thinking, "truth divorced from interpretation is fatuous' (Murphy, 1988: 601). Discourse is the means through which interpretation is undertaken.

The use of discourse varies widely. Sometimes it is related directly to the instrumentalities of governance and power (Hajer, 2005: Richardson and Jensen, 2003). Sometimes it is treated as part of a renewed participatory and collaborative ethics of 
practice (Healey, 1998: Upton, 2002). Whatever the use, analysis of policy as discourse begs an almost obvious question. How is discourse related to reality and in relation to urban planning and urban policy, how is discourse related to places and spaces?

The discussion proceeds from the general to the specific. It starts with a general theory of human understanding and then proceeds to more specific interpretations in urban geography and urban design. As will be argued throughout, both postmodernism and the discourse of space imply the use of triadic structures, that is to say structures that comprise three elements and triangular thinking that relate one element to the other two.

\section{Distinguishing between the real and reality: rethinking the planning process}

A suitable starting point is a distinction between the 'real' and 'reality', with the 'real' defined as the remainder of what is left over after other aspects of reality are understood. Some clarification is required. The distinction between real and reality refers to the work of Lacan, a French theorist of the 1950s and 1960s, who sought to apply linguistic analysis to the development of the human personality or, to use a more specific theoretical term, the human 'psyche'. Lacan was a psychoanalyst, that is to say a researcher who considered the feasibility of working out mental processes merely from talking to people and uncovering their hidden fears and desires. For Lacan, the psyche can be conceived in the most general terms as the integration of three different elements, each tied to a different stage of childhood development (Julien, 1994; also see Felluga, undated):

- The real is the first and most basic stage of childhood development and knowledge. It is about basic needs that can hardly be articulated;

- The imaginary is the stage when children start to become conscious of themselves as individuals and start to consider alternative images. It is about demands and desires;

- The symbolic is when they relate to other people and in particular to authority figures the 'big other'.

Each element of the triad, each sphere of understanding overlaps each and are all knotted together (Julien, 1994), as shown in the figure below. The arrangement has similarities to a simple Venn diagram where three variables overlap each other. Lacan's triad is slightly different in that the three spheres of understanding interact with one another in three dimensions. The rings are locked together. If one sphere of understanding disappears or becomes imbalanced against the others, understandings of reality are likely to become unstable. The task of analysis is, in other words, to follow the distinctive logic of each, whilst also recognising their interdependence. 


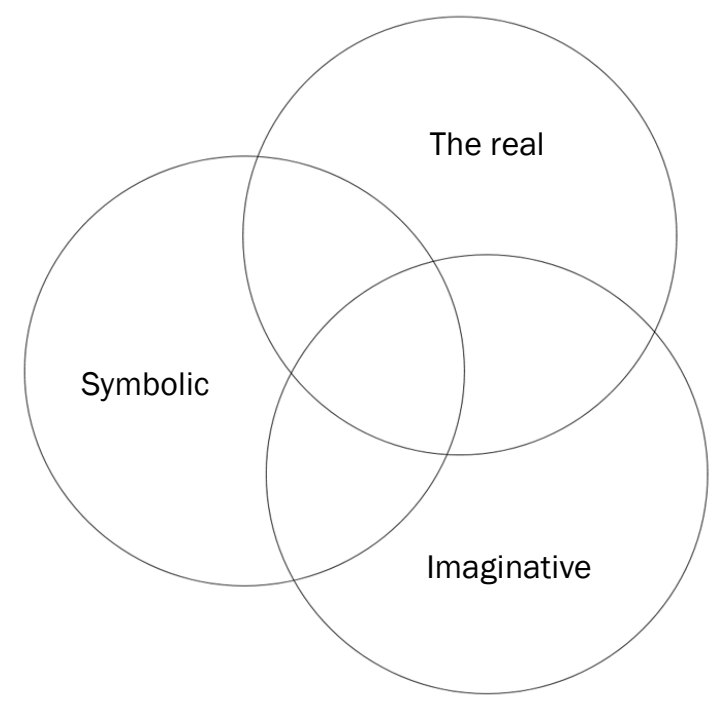

Figure 5:1 Lacan's three spheres of understanding

The real remains an uncertain primordial state. In the words of one interpretation, "the Real is that dimension both of one's own body and of the rest of the world that is neither captured nor controlled by the Symbolic or the Imaginary register' (Bracher, undated). The real is roughly the equivalent of the unconscious in psychoanalysis, a partly unknowable force that trips up plans and assumptions about how the world works and that cannot be fully expressed through language. 'Real' is the point of resistance, the traumatic 'indivisible remainder' that resists symbolization.' (Žižek, 2003: 2). In relation to planning, the real has also been described a paranormal force- a haunting that is outside conventional understanding (Gunder, 2008).

Referring to paranormal forces in the context of planning or urban policy is troubling. For some critics such as Sokal and Bricmont (1999), postmodernism, Lacan and discourse analysis included, deny the knowability of reality, deny the possibility of rational action and suggest, in effect, that people live in a fantasy land. Knowledge becomes purely relative to the subject orientation of different actors and, as part of this, to their unconscious needs. The critics' case is, moreover, strengthened by examples where Lacan and other postmodern thinkers have made naïve comments about science, notably mathematics, as well as by impenetrable character of some of the literature. It is, for example, far easier to summarise Lacan's ideas from the work of interpreters than from the original sources.

The question is to find a 'middle way' between rationality and irrationality. One formulation amongst Lacanian theorists is to suggest that rationality, as applied to both science and common-sense behaviour is about pushing back the boundaries of knowledge. The very sense of the real can be interpreted as the driving force for science and research (Benedikter, undated). The unknowns of knowledge and the unknowns of science are a 'productive void', driving along a process of innovation and the development of new techniques and scientific knowledge. 
Another interpretation is to look at the triad from the perspective of social theory (rather than psychoanalysis) and to define the real as capital, that is to say the workings of the global economy and its representation in the form of particular industries and markets. Capital is an impersonal force, in the words of Žižek (1999: 276), "real in the precise sense of determining the structure of ... material social processes: the fate of whole strata of populations and sometimes of whole countries'. Equally, it is often an unpredictable force. For example, few housing and property analysts predicted the decline in house prices that took place in Britain, the US and most European countries in the second half of 2007 and that was the main cause of the drop in house building completions. At the same, capital is at least researchable. The 'real', defined as need or capital is not an incoherent, undifferentiated mass. It can be analysed and observed in a way that reveals its internal distinctions, structures, as well as its broader logic. In saying this, moreover, a postmodern analysis has parallels to the arguments that property market analysts and consultants have advanced for pragmatic reasons. A combination of quantitative and qualitative methodologies is preferable, one that considers a variety of different perspectives and is for this reason pluralist in character (see Guy and Henneberry, 2000: Wallace, 2004.).

The real, so understood, has been interpreted in planning theory as implying a style of intervention that is based on 'indeterminacy and contingency' (Hillier, 2003: 41) and that, as a result, recognises uncertainty. The real, though researchable, has disordered and irrational characteristics. The real makes consensus provisional, temporary and conditional. It does this through requiring repeated renegotiation in the context of change. The uncertainties of practice also mean limits to which both practitioners and educators can or should rely simply on facts (Gunder, 2004). Planners, like anyone else, are likely to be influenced by their sense of worth, their ego and by the influence of significant others, notably the profession. The extent to which planners are likely to be able push back the uncertainties of practice is also likely to be constrained by lack of time, by research resources and by the limitations of language.

The real does not, however, as Gunder and Hillier (2004: 223) have argued, deny the possibility of coming to a policy consensus that might fully satisfy different parties. To the extent that social agreements and consensus exist, these belong predominantly to the symbolic realm rather than the real. The symbolic covers politics, law and authority figures or to use contemporary language 'role models' with which an individual might identify. Lacanian theory does not rule out the possibility that an individual might so identity with another as to fully accept his or her views and aims. Limited forms of social consensus are possible within Lacanian theory. Individuals might also accept the legitimacy of the procedures used in coming to a decisions, even if they dislike the decision itself. More than, this, however, Lacanian theory is about socialisation rather than social consensus. It is about the processes that encourage individuals to fit into society, as well as the barriers to socialisation, represented by the individual's unarticulated needs (the real) and their expressed demands.

\section{Classifying the relationship between people and spaces: rethinking urban life}

A socio-economic interpretation of Lacan's triad can be taken further. Classifications of social reality are not confined to theorists working in the tradition of Lacan. A broad resemblance can also been noted between Lacan's real/imaginary/symbolic triad and 
other classifications of spatial practices in urban geography, planning and urban design (Gregory, 1997: Gunder, 2005).

In urban geography, the most widely cited theorist in this context is Lefèbvre, who was a contemporary of Lacan and who, in effect, redefined Lacan's categories into a framework that would facilitate a materialist, economically driven history of space, but would also allow a recognition of the subjective perspective of users. Each type of society, Lefebvre suggested, produces its own type of space and its own type of city. Conversely changing the production of space is itself tantamount to changing society. Changing the production of space and changing society imply a modernist planning agenda, that of social reconstruction. However, the means of changing society and space were different from the modernist, blueprint styles of town planning in vogue for most of the $20^{\text {th }}$ century. Change was to be secured through promoting a 'right to the city', understood as a 'right to a transformed and renewed urban life' (Lefèbvre, 1989: 478). A transformed and renewed urban life meant, in turn, that space had to be understood and classified from a socioeconomic viewpoint.

For Lefèbvre (1991: 38-39), three main aspects are apparent - the "perceived, conceived and experienced." These aspects parallel Lacan's triad, but are the product of social processes rather than the development of the human personality.

- The 'perceived' comprises spatial practices as they exist at any historical period, including the daily routines of the population, their use of time and travelling patterns

- The 'conceived' covers the languages and conventions that allow spatial processes to be talked about and understood. The conceived involves "representations of space"

- The 'experienced' (sometimes translated as the "lived") comprises the world of users and redefines physical spaces in symbolic terms. The experienced involves "the spaces of representation".

The perceived corresponds therefore, in general terms, to the real, particularly to the socio-economic interpretation of the real by Žižek (1999). The conceived may likewise be broadly considered as the equivalent to the imaginary. Finally, the experienced covers the symbolic. As with Lacan's original triad, the three elements overlap and interact with one another. However, there is no reference to these being tied in a three-dimensional knot, as in Lacan's interpretation.

Lefèbvre's classification was endorsed by Harvey (1989: 219) in the context of a broad critique of postmodern urban development. The different elements provided 'a dramatic tension through which the history of spatial practices could be read'. Harvey's main criticism was that Lefèbvre's categories were too vague. Likewise, the classification has been endorsed in general terms in urban design by Madanipour, (1996a: 14), as providing a common language that brings together 'ideal spaces that are the product of mental processes' and 'real space that is the product of social praxis'. The reference to praxis is misleading. Praxis itself has mental aspects. Even so, the idea of the perceived/conceived/experienced triad as linking society and space, people and places, urban policy and urban design is clear enough. 
It is doubtful, however, whether the classification enables an understanding of the production of space, as was Lefèbvre's aim. The classification is more about the social construction of space rather than either space as an object or the production of space in the sense of the specific processes of design, development and construction. As such, it tends to suggest that physical space is somehow outside society. Strictly interpreted, the classification also says little about the sense of place, that is about feelings towards a place (Unwin, 2000). It is spatial practices, representations of space and spaces of representations.

In any case, Lefèbvre implicitly recognised the limitations of 'perceived', 'conceived', 'experienced' triad through the use of another, overlapping triad that sought to classify the scale and location of social practices in urban development. In this context, Lefèbvre (1985) distinguished between three levels of social reality- the level of theory and ideology of architects and planners, including the policy context in which they work; the level of implementation in which architects and planners have to cope with the practical requirements of development and finally the concrete reality of how projects are used.

Each level of social reality and each concept of space overlaps and interacts with each other. Each also contains internal contradictions. Analysis, including the evaluation of urban design has to reveal the tensions and interactions that exist in any specific case. Equally, as part of this, analysis has to recognise a distinction between the intentions of urban designers, planners and policy makers on one hand and the way that users respond to the places where they live. The reality of residents' life-styles and places as experienced has to be tested and assessed against the representation of professionals, whether in the context of modernist projects (Boudon, 1985) or more recently, the new urbanism and Urban Renaissance policy agendas (Thompson-Fawcett, 2003). Goodchild and Cole (2001) have used a similar framework in assessing the practical implications of policies to promote social mix. Again, they have show a divergence between experience on the ground and the intentions of policy makers. However, they also show that social housing agencies, operating at an intermediate level between general policy statements and local residents, adopted an alternative, third position.

\section{Aspects of place: rethinking the task of urban design}

Despite the occasional references to Lefebvre, the most common triadic classifications in urban design in Britain have separate origins, again. They originate in another, similar classification, originally worked out by Canter (1977), apparently independently of both Lacan and Lefèbvre and subsequently adopted as a statement of the characteristics of a place (see, for example, Montgomery, 1998: Tiesdell and Macfarlane, 2007). Canter wrote as a psychologist, with an interest in the workings of the human mind. The subject matter of psychology - the human mind, human understanding and its relation to behaviour - is the same as that of psychoanalysis. However, the methods differ radically. Psychology is based on experiments, surveys and observations rather than theory and lengthy discussions with individual subjects. For Canter, a simple diagram or 'visual metaphor' was necessary to understand the constituents of a place as the interaction between:

- Actions and activities

- Physical attributes (the physical shape and parameters of the setting); and 
- Conceptions (the descriptions that people have of actions and activities, including mental maps, mental images and classifications of desirability and undesirability).

Sometimes a distinction is made in social psychology between conception (mental route maps) and perceptions (assessments of desirability and value). However, these are typically blurred together in discussions of urban design, as well as in Canter's original. The result is a Venn diagram with place at its core, as shown in the following figure.

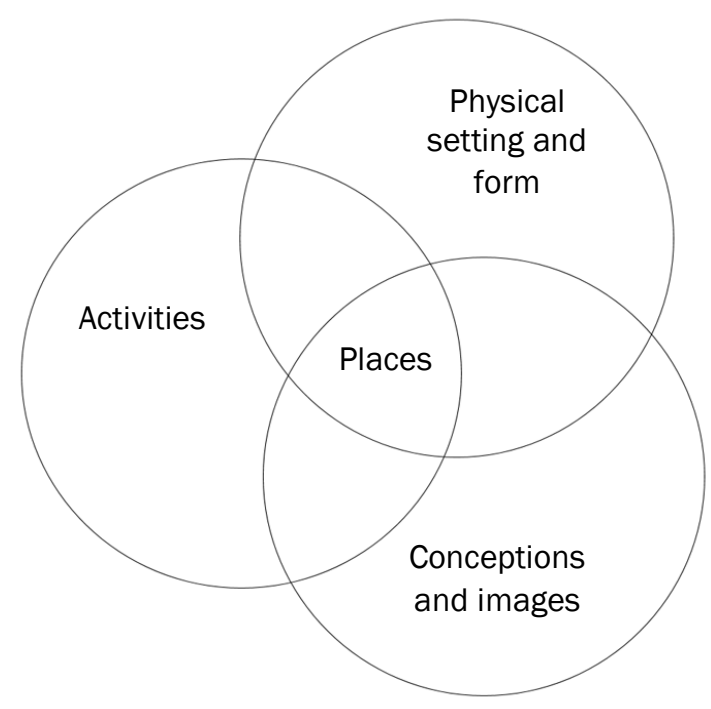

Figure 5:2: A diagrammatic representation of the characteristics of a place

Design can start anywhere. It has to deal with the various parts - activities, physical setting and conceptions. Moreover, the parts can be further subdivided, as necessary. Montgomery (2003) has, for example, used the framework to specify a set of indicators that can be used to assess the success of and case for designated 'cultural quarters' in urban regeneration projects. Each of the three aspects of place generates separate factors that need consideration. Equally, however, urban design has to deal with the whole and with the interaction between the parts.

Much depends on how Canter's physical attributes/activities/conceptions triad is used. The triad can tend towards a view of urban places as objects, as might, of course, be expected from its use in urban design projects. As a result, like other similar urban design concepts, notions of time and change are easily ignored or lost (Madanipour, 1996b).

In contrast, as originally developed by Canter (1977), the physical attributes/ activities/ conceptions triad assumed that the integration of the constituent parts of place took place through a dynamic process of interaction- between individuals and the environment, between individuals and other individuals and between designers and interested parties. Canter (ibid, 161-178) explains how different participants in a design process have 
different starting points, different conceptions and different mental maps and sometimes different activities in mind. Some of these differences refer to different types of users, classified for example by age, gender or class. To provide a specific example, it is possible to demonstrate that the residents of deprived estates generally have a narrower, more closely defined image of a city than others, most likely because of a more restricted set of movement patterns and social networks (Green and White, 2007). Other differences derive from the distinction between users and organisations and the different priorities of different organisations. One might hypothesise, for example, that the mental map of an estate might vary between, say, a police officer and a housing officer. Evaluation of places and evaluation of urban design policy must therefore adopt a pluralist agenda that explicitly recognises different viewpoints.

\section{Conclusions}

Taking all this together, it is possible to indicate a revised triadic classification that attempts to retain the breadth and dynamic elements of Lacan's original with the more specific contributions from geography and urban design. Such a classification might be as follows (Goodchild, 2008: 126):

- The real, understood partly as the material environment, partly as capital and partly as a process that produces spaces and places

- The imaginative, understood as images, imaginary landscapes and other spatial representations, including the various, not necessarily consistent proposals for the future

- The symbolic, understood as the personal and social identities embodied in space and the relation between proposals, communities and significant political actors.

Some qualifications are necessary. Any classification of practice, including the triads of urban design and planning, loses all force if treated as an abstract model (Lefèbvre, 1991: 40). Classifications cannot say much partly because they involve a universal language independent of specific social practices (Harvey, 1989: 222). Historical accounts and accounts of practice have to use the language that is at hand. They have to recognise, in addition, that the language of practice is often ambiguous as to how specific issues correspond to the general distinctions. Users and other interested parties may fuse different aspects into one concept or description.

Nevertheless, the logic of a triad has significant implications. Triads offer an alternative to the type of binary thinking implicit in such distinctions as Left/Right, working class/middle class, inner city/suburbs or physical/social planning. A binary distinction is useful in the words of Lefèbvre (1991: 39) in identifying 'contrasts, oppositions and antagonisms'. A triad, in contrast, is about triangular thinking. So long as an excessively object-oriented view is avoided, triads encourage a reflection of significant effects and interrelationships. They encourage a more reflective approach to practice (ThompsonFawcett, 2003) and a more integrated approach to practice, one that links urban design and urban policy (Madanipour, 1996b). Equally, they enable the evaluation of places to be linked to urban policy evaluation and vice versa.

A triad is moreover not about one element determining the rest, at least not as a universal rule. The relationship comprises a series of mutual dependencies and constraints 
of a type that precludes the discussion of one aspect without eventually touching on the others. In addition, and this is the specific contribution of postmodernism, triangular thinking offers, potentially, a means of explicitly recognizing different viewpoints, the uncertainties of scientific understanding and the role of discourse in moulding understandings of social reality.

*Correspondence Address: Barry Goodchild, Sheffield Hallam University, Sheffield, S1 IWB, UK. Email: B.J.Goodchild@shu.ac.uk

\section{References}

Benedikter, R. (undated) Jacques Lacan and the Discourse of Science, consulted June 2007 at the website of 'Philosophia' at http://www.philosophiaonline.de/mafo/heft2001-02/benedikter_lacan.htm.

Boudon, P. (1985) Pessac de le Corbusier [Le Corbusier's Pessac]. Paris: Bordas [Original 1969]

Bracher, M. (undated) Lacanian Resources for Organizational Consulting consulted June 2006 at http://www.sba.oakland.edu/ispso/html/bracher.html.

Canter, D. (1977) The psychology of place. London: The Architectural Press.

Feindt, P. and Oels, A. (2005) Introduction to the Special Issue: Does Discourse Matter? Discourse Analysis in Environmental Policy Making. Journal of Environmental Policy \& Planning, 7, 3, 161-173.

Felluga, D. 'Modules on Lacan: On the Structure of the Psyche'" Introductory Guide to Critical Theory. Consulted October 2008 at the website of Purdue University at http://www.purdue.edu/guidetotheory/psychoanalysis/lacanstructure.html.

Goodchild, B. (2008) Homes, Cities and Neighbourhoods. Aldershot: Ashgate.

Goodchild, B. and Cole, I. (2001) Social balance and mixed neighbourhoods; a review of discourse and practice in British social housing. Environment and Planning D: Society and Space, 19, 1, 103-122.

Green, A. and White, R.J. (2007) Attachment to place, Social networks, mobility and prospects of young people. York: Joseph Rowntree Foundation.

Gregory, D. (1997) Lacan and Geography: the Production of Space Revisited, in: Benko, G. and Strohmayer, U. (eds.) Space and Social Theory. Oxford: Blackwell, pp .203-231.

Gunder, M. (2004) Shaping the Planner's Ego-Ideal: A Lacanian Interpretation of Planning Education. Journal of Planning Education and Research 23, 299-311.

(2005) 'The production of desirous space: mere fantasies of the Utopian city?' Planning Theory, 4, 2, 173-199.

Gunder (2008) Ideologies of Certainty in a Risky Reality: Beyond the Hauntology of Planning. Planning Theory, 7, 2, 186-206.

Gunder, M. and Hillier, J. (2004) Conforming to the Expectations of the Profession: A Lacanian Perspective on Planning Practice, Norms and Values. Planning Theory \& Practice, 5, 2, 217-235.

Guy, S. and Henneberry, J. (2000) Understanding Urban development Processes: Integrating the Economic and the Social in Property Research. Urban Studies, 37, 13, 2399-2416.

Hajer, M.A. (1995) The Politics of Environmental Discourse: Ecological Modernization and the Policy Process. Oxford University Press. 
p. 131. Triadic classifications and triangular thinking: their use in urban planning and urban design

Harvey, D. (1989) The Condition of Postmodernity. Oxford: Basil Blackwell.

Hastings, A. (2000) Discourse Analysis: What Does it Offer Housing Studies? Housing, Theory and Society, 17, 3, 131-139.

Healey P, (1998) Building institutional capacity through collaborative approaches to urban planning. Environment and Planning A, 30, 9, 1531-1546.

Hillier, J. (2003) Agonizing over Consensus: Why Habermasian Ideals cannot be 'Real'. Planning Theory, 2, 1, 37-59.

Julien, P. (1994) Jacques Lacan's Return to Freud: The real, the symbolic and the imaginary. New York and London: New York University Press. (Translated from an undated French original.)

Lefèbvre. H. (1985) Préface in Boudon op cit.

(1991) The Production of space. Oxford: Blackwell (French original 1974).

(1998) "Le Droit à la Ville " in Ansay, P. and Schoonbrodt, R. (eds) Penser la Ville, Brussels, AAM Éditions (Extract from an original published in 1968).

Madanipour, A. (1996a) Design of Urban Space. Chichester: John Wiley.

(1996b) Urban design and dilemmas of space. Environment and Planning D: Society and Space 14, 3, 331-355.

Montgomery, J. (1998) Making a city: Urbanity, vitality and urban design. Journal of Urban Design, 3, 1, 93- 116

(2003) Cultural Quarters as Mechanisms for Urban Regeneration. Part 1: Conceptualising Cultural Quarters. Planning, Practice \& Research, 18, 4, 293-306.

Murphy, J.W. (1988) Making sense of postmodern sociology. The British Journal of Sociology, 39, 4, 600-614.

Richardson, T. and Jensen, O.B. (2003) Linking Discourse and Space: Towards a Cultural Sociology of Space in Analysing Spatial Policy Discourses. Urban Studies, 40, 1, 7 22.

Sokal, A. and Bricmont, J. (1999) Intellectual Impostures: Postmodern Philosophers' Abuse of Science. London: Profile.

Tett, A. and Wolfe, J. M. (1991) Discourse Analysis and City Plans. Journal of Planning Education and Research, 10, 3, 195-200.

Thompson-Fawcett, M. (2003) Urbanist' lived experience: resident observations on life in Poundbury. Urban Design International, 8, 1-2, 67-84.

Tiesdell, S. and MacFarlane, G. (2007) The Part and the Whole: Implementing Masterplans in Glasgow's New Gorbals. Journal of Urban Design, 12, 3, 407-33.

Unwin, T. (2000) A waste of space? Towards a critique of the social production of space. Transactions British Geographers, NS 25 pp. 11-29.

Upton, R. (2002) Planning praxis: Ethics, values and theory. Town Planning Review, 73, 3, 253-69.

Wallace, A. (2004) Understanding Local Housing Markets? The need for a complementary institutional approach. York: Centre for Housing Policy, University of York.

Žižek, S. (1999) The Ticklish Subject: Absent Centre of Political Ontology. London: Verso. (2003) 'General Introduction', in: Žižek, S. (ed.) Jacques Lacan: Critical Evaluations in Cultural Theory. London: Routledge, 1-3. 